\title{
CAPÍTULO 74
}

\section{PERCEPÇÃO DE MÃES ADOLESCENTES SOBRE O ALEITAMENTO MATERNO NO ÂMBITO DA ESTRATÉGIA SAÚDE DA FAMÍLIA}

DOI 10.4322/978-65-995353-2-1.c74

\section{Tamires Barbosa Bezerra ${ }^{1}$, Josiliane Pâmela da Silva ${ }^{2}$, Carla Virgínia Souza Gonçalves}

Lima $^{3}$, José Nairton Coelho da Silva ${ }^{4}$, Ewerton Pereira Lima ${ }^{5}$, Paulo Ivany de Souza ${ }^{6}$, Maria Nazaré Negreiros Uchôa ${ }^{7}$, Aline de Oliveira Caldeira ${ }^{8}$, Antonia Francielia de

\author{
Aguiar Lima9, Solange de Freitas Lavor ${ }^{10}$ \\ ${ }^{1}$ Universidade Regional do Cariri, (tbbtami@gmail.com) \\ ${ }^{2}$ Universidade Regional do Cariri, (josi-liane@hotmail.com) \\ ${ }^{3}$ Universidade Regional do Cariri, (carla.2vivi@ hotmail.com) \\ ${ }^{4}$ Centro Universitário Dr Leão Sampaio, (nairton201515@yahoo.com.br) \\ ${ }^{5}$ Universidade Regional do Cariri, (ewrtonplima@gmail.com) \\ ${ }^{6}$ Universidade Regional do Cariri, (pauloivany@ hotmail.com) \\ ${ }^{7}$ Universidade Regional do Cariri, (naza.uchoa@ hotmail.com) \\ ${ }^{8}$ Universidade Regional do Cariri, (licaldeira89@gmail.com) \\ ${ }^{9}$ Faculdade Vale do Jaguaribe (francielias5@ gmail.com) \\ ${ }^{10}$ Universidade Regional do Cariri, (sollavor2015@gmail.com)
}

\section{Resumo}

Introdução: O aleitamento materno é considerado a principal fonte para atender aos aspectos nutricionais, psicológicos e imunológicos do lactente no seu primeiro ano de vida. A amamentação apresenta inquestionáveis vantagens, configurando-se como a mais saudável das estratégias de saúde tanto para a mãe quanto para a criança, e o conhecimento acerca deste ato permite um impacto positivo na promoção integral à saúde do binômio mãe-filho. Objetivo: Conhecer a percepção de mães adolescentes acerca do aleitamento materno. Método: Pesquisa com abordagem qualitativa, sendo um estudo de campo, do tipo descritivo, onde a coleta de dados deu-se nos meses de fevereiro a março de 2017 a partir de uma entrevista semiestruturada. Participaram da pesquisa 10 adolescentes, de uma UBS localizada no interior do Estado do Ceará, com faixa etária entre 12 a 18 anos. As respostas obtidas foram agrupadas em categorias temáticas a partir da leitura e análise dos dados. Resultados: Verificou-se que as adolescentes ainda possuem dificuldades acerca do

\section{E - book Tripé do Ensino Superior: Ensino, Pesquisa e Extensão}


reconhecimento do processo da lactação/amamentação implicando em resultados negativos para realização da amamentação. Considerações Finais: Identificamos com este estudo que as adolescentes necessitam ter mais incentivo e informações sobre o aleitamento materno, quanto aos seus benefícios para a saúde materna e infantil, e, que a educação em saúde como ferramenta desse processo necessita ser incorporada com mais ênfase.

Palavras-chave: Aleitamento materno; Estratégia Saúde da Família; Gravidez na adolescência.

Área Temática: Ciências da Saúde.

E-mail do autor principal: tbbtami@gmail.com.

\section{INTRODUÇÃO}

O aleitamento materno é uma das maneiras mais eficazes de atender aos aspectos nutricionais, psicológicos e imunológicos do lactente no seu primeiro ano de vida, sendo assim, é considerado um sinônimo de boa sobrevivência para a criança. Dessa forma, recomenda-se que todas as crianças devam receber exclusivamente o leite materno até os seis meses de idade, e que a amamentação deve ser mantida pelo menos até os dois anos (BRASIL, 2015).

A amamentação apresenta inquestionáveis vantagens tanto para criança quanto para a mãe. Pode-se dizer que se configura como a mais sábia das estratégias de vínculo, afeto, proteção e nutrição da criança. Constitui uma intervenção sensível, econômica e eficaz para a redução da morbimortalidade infantil por doenças infecciosas em geral, especialmente por diarreias, pneumonias e sepse neonatal, além de reduzir a frequência de doenças alérgicas agudas e crônicas e aumentar sua capacidade cognitiva e intelectual, se sobressaindo em permitir um impacto positivo na promoção de saúde integral (TAMASIA, 2013).

O aleitamento é um ato de amor que envolve carinho, atenção e paciência, que exige um comprometimento da mãe para com o filho, proporcionando afeto e saúde, tornando o vínculo mais intenso, ofertando estímulos saudáveis sensoriais, auditivos, táteis, visuais e emocionais. Contudo, a amamentação pode ser uma fase muito complicada, principalmente para as mães que estão amamentando pela primeira vez, e, com isso surgem os inúmeros problemas que podem ser evitados com orientações dadas desde o início da gravidez (OLIVEIRA; NUNES, 2021).

No entanto, percebe-se que as mulheres mesmo cientes da importância do leite materno, não aderem a esta prática devido às dificuldades enfrentadas principalmente nos primeiros dias após o parto, ou não o mantém devido aos traumas mamários que podem

\section{E - book Tripé do Ensino Superior: Ensino,} Pesquisa e Extensão 
ocorrer, tais como: fissuras mamilares, ingurgitamento mamário e mastite devido a má pega, causando dor e desconforto, entre outros. Além disso, pode haver crenças culturais que interferem nessa adesão, principalmente as relacionadas ao entendimento do leite ser fraco e não suprir as necessidades nutricionais da criança, quando ofertado de forma exclusiva. Por isso, a ato de amamentar exclusivamente por seis meses torna-se uma dificuldade para muitas mães (SILVA et al., 2019).

Diante disso com o intuito de ampliar o conhecimento a respeito da saúde de mães adolescentes, têm-se como ferramenta essencial a educação em saúde, ou seja, no que concerne a amamentação, podemos observar que através de intervenções educativas bem estruturadas e elaboradas pode se conseguir o sucesso da prática do aleitamento materno pelo menos até o $6^{\circ}$ mês de vida. A intervenção educativa tende a se tornar um aliado em potencial para o estimulo ao aleitamento materno, para isso os profissionais de saúde necessitam não somente ter conhecimentos e habilidades, mas estarem bastante sensibilizados para incorporá-los em sua prática (FILHO; NETO; MARTINS, 2011).

Entre os profissionais envolvidos no processo da amamentação, destaca-se o profissional enfermeiro, pela sua estreita relação com as mães, a qual se inicia durante as consultas de pré-natal e têm-se a chance de abordar temas indispensáveis para a eficácia do mesmo, como aspectos relacionados ao incentivo do aleitamento materno. Além disso, o profissional tem a possibilidade de continuar ofertando orientações sobre o aleitamento no período puerperal e durante o acompanhamento e avaliação do bebê nas consultas de puericultura (AZEVEDO et al., 2009).

A realização deste estudo justifica-se pelo fato de a adesão ao aleitamento materno ser um ato de suma importância para a saúde materna e infantil, necessitando de intervenções contínuas que favoreçam e fortaleçam essa prática. Para tanto, a educação em saúde configura-se como uma ferramenta poderosa diante dessaimplementação.

Sabe-se que mesmo com todos os benefícios nutricionais e imunológicos que o leite materno tem a ofertar para a promoção de saúde da criança e da mãe, o desmame precoce ou a falta de adesão ao aleitamento materno ainda vem sendo uma grande problemática, devido à falta de informações ou falha das mesmas, por processos culturais ou por percepções errôneas acerca da lactação.

\section{MÉTODO}

A pesquisa se constituiu em um estudo de caráter descritivo, exploratório com 
abordagem qualitativa. Teve como cenário uma Unidade Básica de Saúde (UBS) localizada no município de Iguatu, no interior do Estado do Ceará (CE).

A pesquisa foi realizada com mães adolescentes na faixa etária dos 12 aos 18 anos, que estavam cadastradas na área de abrangência da unidade de saúde selecionada para o estudo, que aceitaram participar da pesquisa e tiveram a devida autorização, mediante assinatura do termo de consentimento assinado pelos pais ou responsável maior. Os critérios de inclusão foram: as que estavam na faixa etária da adolescência, que tivessem parido há menos de um ano que antecedeu a coleta de dados, e que estavam cadastradas na referida UBS. Entretanto, foram excluídas aquelas que não estavam na UBS no momento da coleta de dados.

A coleta de dados se fez através de uma entrevista semiestruturada. Os dados foram analisados através da técnica de Análise de Conteúdo, mediante transcrição das falas sem qualquer alteração do pesquisador, garantindo a fidedignidade dos dados coletados.

A análise de conteúdo aconteceu em três etapas definidas como pré-análise, que consistiu na leitura e organização do material; exploração do material, em que se realizou a codificação, com os devidos recortes do texto e construção de unidades temáticas, classificação e agregação dos dados; e, por fim, o tratamento dos resultados alcançados e sua exploração (BARDIN, 2009). Para que fosse garantido o anonimato das participantes da pesquisa foram utilizados pseudônimos na categorização dos dados, assim, as adolescentes foram referidas por $\mathrm{AD} 1, \mathrm{AD} 2, \mathrm{AD} 3$, e assim sucessivamente.

A pesquisa foi realizada após assinatura do termo de anuência, com a devida autorização pelo município. Assim, a pesquisa atendeu aos preceitos éticos e legais da Resolução No 466/2012, do Conselho Nacional de Saúde (CNS), e obteve aprovação do Comitê de Ética da Universidade Regional do Cariri, com o número do Parecer 2.182.278.

\section{RESULTADOS E DISCUSSÃO}

Participaram da pesquisa, 10 mães adolescentes, sendo predominante a faixa etária entre 16 a 18 anos. Em relação ao nível de escolaridade, a maioria possuía ensino médio incompleto $(44,4 \%)$. Além disso, prevaleceu o estado civil solteira $(88,8 \%)$ e todas as participantes relataram que não trabalhavam formalmente, se dedicando apenas às atividades diárias do lar.

Além dos dados sociodemográficos, também foram contextualizadas as respostas dadas pelas participantes da pesquisa durante as entrevistas, que foram abordadas de modo a 
apresentar os resultados obtidos e a discussão com os achados na literatura.

O aleitamento exclusivo até seis meses de idade tem grande relevância para o crescimento e desenvolvimento da criança. Sem exceções, outro nenhum alimento ou leite industrializado modificado se mostra eficaz em ofertar ao bebê todos os componentes do leite materno (FILAMINGO et al., 2012).

Para que as adolescentes amamentem de forma eficaz e que entendam a importância desta ação no intuito de melhorar na sua prática diária para com o seu filho, é essencial que estas conheçam todas as informações necessárias sobre o leite materno bem como os seus benefícios. Diante disso a pesquisa buscou conhecer o que as adolescentes entendem por aleitamento materno.

Através das respostas obtidas pode-se perceber que ainda existe uma falta de reconhecimento do que se trata esta ação, mesmo que consigam reconhecer a importância da prática e que as realizaram até pelo menos os seis meses de vida da criança. Algumas entendem o ato do aleitamento materno apenas superficialmente, e outras apresentaram maiores explicações, conforme evidenciado pelas falas dispostas no Quadro 1.

Quadro 1 - Falas das participantes da pesquisa retratando o entendimento que possuem acerca do aleitamento materno.

\begin{tabular}{|l|l|}
\hline AD6 & "É uma ação importante e essencial para o crescimento saudável da criança e \\
& da mãe, além de garantir benefícios infinitos para ambos. " \\
\hline AD2 & "É quando a mãe se dedica totalmente amamentação exclusiva para o seu \\
bebe."
\end{tabular}

Fonte: Autores, 2021.

Araújo (2013) ressalta que o grau de instrução materna tem influenciado na motivação para amamentar. Pois em muitos países desenvolvidos, mães com maior grau de instrução tendem a amamentar por mais tempo, pelo fato de um maior acesso a informações sobre as vantagens do leite materno. Logo, as mães com menor escolaridade e menos instruídas, por vezes não casadas, iniciam o pré-natal mais tardiamente, e, por consequência se preocupam em definir sobre a alimentação do bebê também mais tarde.

Com base nos inúmeros benefícios que o leite materno tem a ofertar a saúde maternainfantil, atuando diretamente no desenvolvimento cognitivo do bebê, ao prevenir o surgimento de alergias, anemias e infecções respiratórias e a importância do conhecimento das mães acerca dessa temática, o estudo buscou identificar a visão das adolescentes acerca dos benefícios do aleitamento materno. 
Através das respostas dadas pelas participantes, pode-se observar que estas possuem pouco ou nenhum conhecimento sobre as reais vantagens ofertadas pelo aleitamento para o binômio mãe-filho, reconhecendo-o na maioria das vezes como um ato que beneficia apenas a criança, conforme apresentado no Quadro 2.

Quadro 2 - Falas das participantes da pesquisa retratando sobre a percepção que possuem acerca dos benefícios do aleitamento materno.

\begin{tabular}{|l|l|}
\hline AD7 & $\begin{array}{l}\text { "Para mim nada, mas para minha filha para ajudar na alimentação e nos } \\
\text { dentinhos. }\end{array}$ \\
\hline AD3 & "É bom para nascimento de dente porque não dá febre e nem sintomas" \\
\hline AD9 & "Não sei." \\
\hline
\end{tabular}

Fonte: Autores, 2021.

Martins e Silva (2013) encontraram inexatidões semelhantes aos relatos das adolescentes, e afirmam perceber uma falha dos profissionais de saúde em não informar e oferecer de forma direta ações que as disponibilizam as vantagens que o corpo da mulher sofre quando escolhe o aleitamento exclusivo.

Dessa forma, existem diversos aspectos que não podem ser desconsiderados, quanto ao desconhecimento das vantagens ofertadas pelo leite materno tanto para mãe quanto para o filho, que seriam a possibilidade de a adolescente ter sido orientada e não se lembrar as recomendações (TAKEMOTO et al., 2011).

Compreendendo a lactação como um método complexo, que requer dedicação, paciência e muito afeto, dependente de inúmeros mecanismos controlados por hormônios cuja sintonia entre mãe e filho é indispensável, e que frente a isso a adolescente pode enfrentar algumas dificuldades para realizar a amamentação, buscou-se identificar se há essas dificuldades, na percepção das adolescentes.

De acordo com as falas, pode-se perceber que as adolescentes possuem algumas dificuldades para conseguir realmente amamentar seu filho, conforme apresentado no Quadro 3.

Quadro 3 - Falas das participantes da pesquisa retratando sobre a existência de dificuldades para realizar a amamentação.

\begin{tabular}{|l|l|}
\hline AD8 & “Amamentei! A minha filha não queria pegar o peito." \\
\hline AD3 & "Não amamento. Dói quando tá sugando o leite." \\
\hline
\end{tabular}

\section{E - book Tripé do Ensino Superior: Ensino,} Pesquisa e Extensão 


\begin{tabular}{|l|l|} 
AD4 & "Dei de mamar mais o leite era fraco e o meu filho não engordava."
\end{tabular}

Fonte: Autores, 2021.

Shimodai e Silva (2010) encontraram dados que corroboram com os achados do presente estudo, pois trazem que apesar do conhecimento materno sobre os benefícios do leite materno e da importância de amamentá-los exclusivamente durante os seis meses, elas vivenciam dificuldades onde se percebe contradições favoráveis e desfavoráveis, dúvidas e dificuldades á prática do aleitamento materno.

Amamentar é um processo complexo e, quando se fala em adolescentes lactantes, tornase ainda mais problemático e, embora, existam campanhas de incentivo a amamentação, o processo ainda não é uma prática frequente, principalmente em casos de mães adolescentes. Sendo adolescente ou não, as mães requerem orientação e suporte objetivando o desenvolvimento de habilidades para amamentar (TAKEMOTO et al., 2011).

De acordo com o exposto, compreende-se que é fundamental que se ofertem informações e ações para o enfrentamento das dificuldades que possam a vim ser relatadas pelas mulheres, principalmente as primíparas, pois estas necessitam compreender os fatores que podem está estreitamente relacionados as estes problemas enfrentados durante o período de lactação.

Dessa forma, entende-se que através das falas das adolescentes, que é necessário as ações de educação em saúde, com informações sobre as possíveis problemáticas associadas à amamentação, para que as lactantes estejam orientadas e conscientes sobre como proceder, contribuindo para um processo de eficácia da amamentação, haja vista que a informação é uma das ferramentas mais eficazes para se obter bom desempenho das ações esperadas.

Diante disso, a pesquisa procurou verificar se as adolescentes recebem ou receberam orientações e incentivo sobre amamentação e quem as forneceu, bem como se essas usuárias participaram de alguma ação de educação em saúde e o que podiam opinar sobre tais ações.

Assim, a partir das falas, notou-se que as adolescentes relatam terem sido orientadas quanto à prática da lactação, porém a maioria expressou não havia participado de momentos específicos, ou até mesmo que desconhecia o que significava as ações de educação em saúde, deixando nítida a curiosidade em conhecer e vivenciar ações de saúde voltadas para amamentação, como pode ser verificado no Quadro 4.

Quadro 4 - Falas das participantes da pesquisa retratando sobre a participação de ações de educação em saúde.

AD1 "Sim, a enfermeira que acompanhou minha gestação. Acho legal, mas não tive incentivo de ninguém para participar. Gostaria muito de ter 


\begin{tabular}{|l|l|}
\hline & participado. \\
\hline AD3 & “A dotora, mas não teve nenhuma ação dessa. \\
\hline AD9 & $\begin{array}{l}\text { "Sim. As médica de Fortaleza e as daqui. Participei. Foi importante porque } \\
\text { aprendi muitas coisas com as explicações }(. . .)\end{array}$ \\
\hline
\end{tabular}

Fonte: Autores, 2021.

A intervenção educativa é uma estratégia potencial para o estímulo à lactação. Para isso, os profissionais de saúde, especialmente os de enfermagem, precisam não só ter conhecimento e habilidades, mas serem humanizados o suficiente para incluí-la em sua prática.

Estudos mostram que muitas informações oferecidas às mães referente à prática de aleitamento materno pelos profissionais de saúde, são insuficientes, principalmente quando promovidas apenas no puerpério imediato. Diante disso, é relevante destacar a importância do acompanhamento dos profissionais da Estratégia de Saúde da Família (ESF) no apoio e acompanhamento da prática do aleitamento materno, devendo possuir capacidade para atuar frente a esta tarefa, para dessa forma, auxiliar a superar as dificuldades precoces encontradas na lactação apresentadas pelas nutrizes adolescentes, buscando ampliar as estratégias de educação em saúde (TAKEMOTO et al., 2011).

\section{CONSIDERAÇÕES FINAIS}

Percebeu-se que a complexa determinação da amamentação é condicionada por fortes e diferentes fatores socioculturais, psicológicos e fisiológicos, sendo ampla a rede de questionamentos que interferem nessa prática. As adolescentes ainda possuem um conhecimento deficiente, percebendo que o leite materno tem relevância para a saúde delas e do filho, mas não sabem ao certo os seus benefícios ofertados.

Na prática da amamentação, as adolescentes, revelaram-se comprometidas com esta função, e que buscam dentro do seu contexto de vida desempenha-las adequadamente. Porém, pode-se evidenciar que ainda há uma necessidade de uma oferta maior de informações que desmitifiquem os rótulos ainda existentes, para que estes não sejam enquadrados como barreiras encontradas para se ofertar amamentação.

Evidenciou-se a necessidade da implementação e criação de estratégias que possibilitem conhecer as mães de maneira integrada com seus familiares e comunidade. Desta forma o processo de gerenciamento tem que ultrapassar algumas singularidades,

\section{E - book Tripé do Ensino Superior: Ensino, Pesquisa e Extensão}


rompendo os modelos administrativos, abrindo espaço para novas ferramentas que possam possibilitar o profissional enfermeiro a elaborar atividades de ações educativas que sirvam de incentivo à amamentação.

\section{REFERÊNCIAS}

ARAÚJO, J. P. Desmame precoce e suas causas: experiência na atenção básica de Campina

Grande- PB. Revista da Universidade Vale do Rio Verde, v. 11, n. 2, p. 146-155, 2013.

AZEVEDO, D. S et al. Conhecimento de primíparas sobre os benefícios do aleitamento materno. Rev. Rene, v. 11, n. 2, p. 53-62, 2010.

BARDIN, L. Análise de conteúdo. São Paulo: Edições 70, 2011.

BRASIL. Ministério da Saúde. Secretaria de Atenção à Saúde. Departamento de Atenção Básica. Saúde da criança: aleitamento materno e alimentação complementar. Brasília, 2015.

OLIVEIRA, C. P. A; NUNES, J. S. S. Aleitamento materno e o papel do enfermeiro. Research, Society and Development, v. 10, n. 7, p. 1-10, 2021.

FILAMINGO, B. O. et al. A prática de aleitamento materno entre mães adolescentes na cidade de Dois Córregos. Rev. Scientia Medica, v. 22, n.2, p. 81-85, 2012.

FILHO, M. D. S; NETO, P. N. T. G; MARTINS, M. C. C. Avaliação dos problemas relacionados ao aleitamento materno a partir do olhar da enfermagem. Cogitare Enferm, v. 16, n. 1, p. 70-75, 2011.

MARTINS, M. Z.O; SILVA, L. S. Benefícios da amamentação para a saúde materna. Interfaces e Ambiente, v.1, n.3, p. 87- 97, 2013.

SHIMODAI, G. T; SILVA, I. A. Necessidades de saúde de mulheres em processo de amamentação. Rev Bras Enferm, v. 63, n. 1, p. 58-65, 2010.

SILVA, Y. J. A et al. Dificuldades no aleitamento materno na maternidade da fundação santa casa de misericórdia do Pará e o apoio do banco de leite. Revista Eletrônica Acervo Saúde, 
v. 11, n. 5, p. 1-14, 2019.

TAKEMOTO, A. Y et al. Preparo e apoio à mãe adolescente para a prática da amamentação. Rev Cien Cuid Saúde, v.10, n.3, p. 444- 451, 2011.

TAMASIA, G. A. Perfil da amamentação e alimentação complementar no Município de Registro-SP. Dissertação (Mestrado em Ciências). Faculdade de Saúde Pública, Universidade de São Paulo. São Paulo, p. 140, 2013. 